\title{
Estética y ética de la imagen del otro. Miradas compartidas sobre fotografías de indígenas del Chaco ${ }^{1}$
}

\section{Aesthetics and Ethics of the Image of the Other. Shared Viewpoints of Chaco Natives' Photographs}

\author{
Mariana Giordano. \\ Instituto de Investigaciones geohistóricas-CONICET / Facultad de Humanidades, \\ Universidad Nacional del Nordeste. Chaco-Corrientes, Argentina \\ marianagfav@ciudad.com.ar
}

Resumen •El artículo propone un análisis de un conjunto de fotografías históricas del indígena del Chaco argentino a partir de un cruce de miradas del investigador y de las comunidades indígenas actuales. Ello supone la necesidad de discutir no sólo sobre la «sinceridad estética» en las producciones históricas y reproducciones contemporáneas, los modos hegemónicos de construcción de sujetos históricos y de identidades sociales, sino también, y esencialmente, sobre la «ética» de las producciones contemporáneas, la ética de la circulación de imágenes del indígena y la ética de la recepción de estas imágenes en la actualidad. Se promueve así un diálogo que apunta a debatir los conceptos de reflexión e inflexión en la percepción de las imágenes.

Palabras claves: indígenas, Chaco, fotografías, ética, estética.

Abstract - The following paper proposes to analyze historical photographs of the Argentine Chaco indigenous people from both a scientific point of view and the indigenous communities' one. It is necessary to discuss not only the "aesthetic sincerity» of historical and contemporary productions and the hegemonic forms that construct historical subjects and social identities, but also the ethics of contemporary productions, ethics of the indigenous images circulation and the ethics of receiving these images today. The article proposes a dialogue to discuss the concepts of reflection and inflection in the perception of images.

Keywords: indigenous, Chaco, photographs, ethics, aesthetic.

1 El presente trabajo se enmarca dentro de los Proyectos «Captura por la cámara, devolución por la memoria. Imágenes fotográficas e identidad» (PIP 6548 CONICET) y «Memoria e imaginario en el Nordeste Argentino. Escritura, oralidad e imagen» (PICTO-UNNE 130). 
La imagen fotográfica ha sido objeto de diversas formas de aproximación teórico-metodológica en las últimas décadas, en particular desde que las ciencias sociales dejaran de considerarla como una mera ilustración fundada en una supuesta transparencia de la imagen, para considerarla «artefacto» y «medio» ${ }^{2}$. Las diversas perspectivas de abordaje — desde la estética, la antropología, la historia del arte, la semiótica, la antropología, etc.- han encontrado sin embargo, ciertos límites al tratar imágenes que han tenido como objeto/ sujeto a los grupos indígenas: si bien en general se alude al contexto de colonialismo en que ellas han sido obtenidas, se hace hincapié en la relación asimétrica entre el fotógrafo y el fotografiado - y de allí la mayor violencia ${ }^{3}$ que puede emanar de estas tomas-, son escasamente tenidas en cuenta las experiencias visuales de los mismos grupos fotografiados respecto de «sus» fotografías. Experiencias que podrían ubicarse - o no- en otra cara de la moneda no sólo por tratarse de las comunidades que fueron objeto/sujeto de representación, sino porque los modelos analíticos y los actos de recepción varían culturalmente. Pero también se ha prestado escasa atención a los usos y circulación de estas imágenes, o que supone considerar su utilización y manipulación discursiva ubicándose no solamente en una estética sino también en una ética de la imagen ${ }^{4}$ que articule diferentes miradas, no sólo la del analista-científico sino también las de las propias comunidades indígenas que desconocen estas imágenes.

En momentos en que se habla de la "iconosfera», en que se debate sobre la producción y uso de las imágenes, estas fotografías de indígenas siguen participando del círculo de captura, manipulación y uso acrítico, en el que diversas instituciones, medios y poderes intervienen. Se cuestionan las producciones históricas-colonialistas de las imágenes de indígenas, pero en los usos actuales que se hacen de ellas se descuida la reproducción de imaginarios y estereotipos históricos. Al observar una imagen no se realiza, por consiguiente, una «inflexión» de algunas creencias y representaciones ordinarias, o podríamos decir, cierta focalización peculiar de nuestras representaciones e intereses (Lizarazu, 2008), centrándonos sólo en la «reflexión» sobre las mismas.

En este trabajo ensayaremos un análisis sobre un corpus de fotografías de indígenas del Chaco argentino obtenidas por diferentes actores sociales desde fines del siglo XIX hasta la década de 1960: desde nuestra perspectiva de investigador donde nuestro trabajo ha sido una permanente «reflexión» sobre las imágenes de indígenas chaqueños, nos centraremos en esta oportunidad en diversos elementos procedentes de los estudios culturales y visuales, en particular en los modos en que se construye visualmente lo social ${ }^{5}$, o la manera en que desde marcos discursivos y epistémicos diferenciales se piensa en lo visual. Así, el análisis supone la consideración de nuestros propios parámetros de análisis sobre las imágenes promoviendo un diálogo entre la «reflexión» y la «inflexión», por un lado, y las miradas que proceden de las comunidades indígenas actuales en quienes los actos de inflexión desbordan cualquier especulación reflexiva, aunque mediatizados por nuestros intereses en la investigación y por nuestro acercamiento a las imágenes. El objeto de análisis no son,

2 Belting distingue a la imagen como «artefacto» (obras en imagen) y como "medio» (medios en que se comunica esa imagen, tanto en su pieza única como reproducible). Ambos aspectos aparecen indisolubles en la naturaleza de la imagen (2007: 15-6).

3 Violencia que surge de todo acto fotográfico, porque al decir de Sontag «fotografiar personas es violarlas, pues se las ve como jamás se ven a sí mismas" (2006: 54).

4 Lizarazo plantea que «La ética de las imágenes es en realidad la cuestión de aquello que los seres humanos hacemos con ellas, al producirlas, al ponerlas a circular, al consumirlas" (2008: 11).

5 Mitchell plantea que «la cultura visual es la construcción visual de lo social, no únicamente la construcción social de la visión...» (2003: 26). 
por lo tanto, las fotografías en sí mismas, sino el sentido que ellas asumen desde la mirada de un investigador perteneciente a la cultura hegemónica y desde los grupos indígenas en este péndulo entre reflexión e inflexión. Miradas compartidas, con sentidos diferentes que proceden de los modelos analíticos, los estilos cognoscitivos y la experiencia cultural de la recepción.

Ello supuso la realización de trabajos de campo dentro de las comunidades indígenas del Chaco en el contexto de una investigación dialógica, basada en proyectos previos que realizáramos sobre fotografías atribuidas históricamente a los grupos indígenas chaqueños. Como primera instancia, propiciamos un acercamiento a imágenes de sus antepasados (y de los mismos receptores) de las que desconocían su existencia (Giordano, 2009). Convencidos que de esta manera se revertía el círculo, ya que en principio desconocíamos si las nuevas miradas encontrarían en estas imágenes una dimensión documental, estética, ética o siquiera si las comunidades se interesarían de alguna forma en ellas.

La estética de la fotografía nos brindaba la posibilidad de considerar los factores de producción, de circulación y de recepción del objeto fotográfico, aproximarnos al corpus señalado, indagando el aspecto referencial, formal y material de las imágenes (Soulages, 2001) tanto como el cariz sensible y existencial de la experiencia de recepción. Ello no implica sin embargo, descuidar la dimensión que históricamente se presentó como prueba y verdad de la fotografía: la documental, necesaria a considerar por las percepciones basadas en la mimesis que en la sociedad actual siguen estando presentes, $\mathrm{y}$ de las que las comunidades indígenas contemporáneas no están ajenas.

\section{PÉRDIDAS, RESTOS Y RESCATES EN UNA ESTÉTICA DE LA IMAGEN DEL OTRO}

Desde una estética de la fotografía se afirma que «...lo real, incluido el objeto para fotografiar, es infotografiable» (Soulages: 119), sólo se perciben fenómenos que son a su vez fragmentos temporales y espaciales pero que el sentido común lo percibe como un universo compacto. A la vez, la estética contempla la fotograficidad ubicada en el acto de producción de la fotografía, la que supone pérdidas irremediables en el mismo proceso fotográfico y la irreversibilidad del hecho o acto de captura. Soulages plantea que:

...la fotografía es la articulación de la pérdida y el resto. Pérdida de las circunstancias únicas que originan el acto fotográfico, del momento de este acto, del objeto por fotografiar y de la obtención generalizada irreversible del negativo, en suma del tiempo y del ser pasados. Resto constituido por estas fotos que se pueden hacer a partir del negativo $(2005,136)$.

Si bien ello está haciendo referencia a cuestiones técnicas y elecciones estéticas, también se vincula con lo fragmentario del acto fotográfico y con las opciones estéticas posibles (no sólo las existentes).

Nos interesa en este punto abordar la valoración estética vinculada no sólo al referente, sino también a lo formal y a lo material, tanto en la valoración que históricamente tuvo la fotografía del indígena chaqueño para la sociedad hegemónica, nuestra interpretación actual de dicha valoración y cuál es la reflexión/inflexión que surge de las mismas comunidades.

La exhibición de imágenes históricas de indígenas del Chaco que han comenzado a salir de archivos y formar parte de exposiciones artísticas ha influido en que comenzara a mutar en un público amplio la apreciación meramente documental de estas imágenes y que se co- 
menzara a percibirlas también desde su faz estética. Desde las ciencias sociales ocurre algo similar: la crítica documental plantea que la imagen puede ser valorada como documento de las formas de representar en una época histórica, en lo cual no sólo influye el filtro cultural del fotógrafo, sino también sus elecciones estéticas y limitaciones técnicas, como también las expectativas visuales de un público al que están dirigidas, lo que Baxandall llamaría el «estilo cognoscitivo» de una época (1978: 60). Estos nuevos canales de circulación se suman a las demandas de los grupos indígenas que, al conocer nuestro trabajo de años de recopilación de imágenes, comienzan a solicitar copias para realizar exposiciones, afirmando que su solicitud se funda en «ser un documento de nuestra historia» ${ }^{6}$.

En el ámbito de la producción, a fines del siglo XIX y principios del XX la estética de la representación fotográfica del cuerpo humano en el corpus que analizamos y en otros análogos de espacios y grupos étnicos diferentes presentaban, por un lado, la fotografía antropométrica (Penhos, 2005) y, por otro, la fotografía social. Desde ellos se construyó una visualidad del indígena que fue desde los estrictos cánones de la fotografía criminalística adoptada por los registros antropométricos al espectro no menos estricto y canónico de la puesta en escena del retrato social. La fotografía navegó entre ambos sistemas convencionalizados de representación para la captación y difusión de imágenes del indígena chaqueño. Pose, escena, escenario natural, cultural o «neutro» —este último referido al fondo neutro de la fotografía antropométrica- eternizaron imágenes del «otro» que sumados a recursos de luz natural o artificial contribuyeron en la construcción de estereotipos visuales (Giordano, 2003). Es cierto que han existido "pliegues representacionales», y en ello las imágenes de Guido Boggiani ${ }^{7}$ de indígenas del Chaco paraguayo y las de Hans $\mathrm{Mann}^{8}$ y Grete Stern ${ }^{9}$ del Chaco argentino podrían plantear rupturas en una constante de representación ${ }^{10}$.

Referencia y demanda realizada por un indígena mocoví de El Pastoril, 23 de diciembre de 2007.

Guido Boggiani (1861-1901) artista y comerciante italiano, devenido en explorador y etnógrafo, se radicó en Asunción del Paraguay en 1887 y sus contactos con grupos indígenas del Chaco despertaron progresivamente sus inclinaciones etnográficas. Estos primeros trabajos fueron complementados inicialmente por el dibujo, para lo que su aprestamiento artístico le proveía una facilidad de registro inigualable. Los detalles de los tatuajes faciales de los grupos caduveo del Matto Grosso brasilero y chamacoco del Chaco paraguayo fueron posteriormente documentados con su pluma. Tras un viaje que realizó en 1896 a Italia, este artista formado en la Academia Brera de Milán y convertido en etnógrafo como consecuencia de su viaje a Paraguay y al interés que le suscitaran los grupos indígenas de la región, se provee de una cámara fotográfica que desde entonces se convierte en su instrumento esencial en las campañas que desarrolla principalmente entre los chamacoco, aunque no abandona el dibujo y realiza algunas pinturas, esencialmente paisajes.

8 Hans Mann fue un fotógrafo exiliado de la Alemania nazi, que se instaló hacia 1936 en la Argentina. A su llegada recorrió el Río Pilcomayo, editando algunas fotos de indígenas de la región en un fascículo con texto de Caribé, y presentando una de ellas en el Salón del Foto Club Buenos Aires en 1938. Poco después de su llegada a Buenos Aires comenzó a trabajar como fotógrafo oficial de la Academia Nacional de Bellas Artes registrando el patrimonio artístico y arquitectónico nacional; tarea que desarrolló hasta 1956 cuando se fue de la Argentina, radicándose en Brasil, donde falleció en 1966.

9 Grete Stern, fotógrafa alemana formada en la Bauhaus, emigra del nazismo instalándose en Buenos Aires, donde desarrolla una vasta carrera en el ámbito fotográfico. En 1958 es invitada por la recientemente creada Escuela de Humanidades de la Universidad Nacional del Nordeste par la participación en un proyecto institucional: se le encargó la documentación fotográfica del indígena chaqueño con vistas a conformar un Museo y archivo en esa institución. Trabajó durante unos meses en tal tarea, regresando en 1959 para trabajar en el Taller de Arte Regional de la UNNE. En 1964, con una beca del Fondo Nacional de las Artes realizó una documentación más amplia sobre la vida y costumbres de indígenas del Gran Chaco. Véase Giordano (2004).

10 Sobre la obra de Boggiani y Stern y la manera en que constituyen rupturas en la construcción homogénea de una imagen del indígena chaqueño, véase Giordano y Reyero (2009). 
Así, el reconocimiento de la dimensión estética de la fotografía del indígena chaqueño ha reparado en la producción de retratos y escenas étnicas, que responden a procedimientos visuales, encuadres, ángulos de toma, escenografía y luz que comparten las diferentes producciones desde fines del siglo XIX hasta la década de 1960. En el retrato:

Predominan las tomas frontales donde el retratado posa erguido mirando de frente a la cámara. La composición es austera con un encuadre cuidadosamente equilibrado y un ángulo de toma frontal, características que le otorgan a estas fotografías una estética severa, sin artilugios y que nos obliga a dirigir la mirada directamente sobre el retratado [Mientras en la escena étnica] los gestos suspendidos, la parafernalia desplegada y la escenografía que enmarca la escena, han sido cuidadosamente dispuestos, para generar una atmósfera y una composición de carácter «étnico». El principio básico de este procedimiento visual lo constituye la delimitación de un espacio connotado como un fragmento de tiempo y lugar. En este verdadero acto teatral los dispositivos como el encuadre y los ángulos de toma siguen operando con la estética del retrato, donde, si bien los personajes están en el centro, la escenografía conformada por diferentes elementos — como árboles o viviendas - también constituye parte fundamental de la composición (Alvarado y Giordano, 2007: 21-2).

Entendemos que un análisis estético, atendiendo a los elementos formales como a los que hemos hecho referencia, es en ocasiones posible desde los especialistas en el abordaje de imágenes, pero en los actos de recepción, quien observa una fotografía, intuitivamente alude a ciertas configuraciones y estructuras que no siempre se verbalizan o se expresan desde un lenguaje formalista. En particular en nuestro trabajo de campo entre las comunidades indígenas chaqueñas, en el que les acercamos el corpus de fotografías que aquí analizamos, se advierten expresiones que aluden a una lectura sobre los elementos formales y materiales de la imagen, y no sólo sobre el referente, aunque éste fuera el punto de mayor interés. La mirada de niños y jóvenes tobas ante una exposición de Grete Stern ${ }^{11}$ constituyen uno de los puntos de vista interesantes respecto del acto fotográfico. La experiencia consistió en que niños y jóvenes de polimodal de la Unidad Educativa $\mathrm{N}^{\circ} 30$ Aida Zolezzi de Florito del Barrio Toba de Resistencia visitaran la exposición, luego de lo cual planteamos un taller plástico donde expresaran aquello que les había interesado de la muestra, realizando posteriormente comentarios verbales de su experiencia y de lo representado en forma visual ${ }^{12}$. En los dibujos y collages que realizaron surgen elementos de análisis que van desde la alusión al referente — reproducción de retratos, espacios y objetos- a construcciones visuales que la imagen observada disparaba y que en el campo de lo denotado no se vinculaba al referente de las fotografías recepcionadas. El uso del color en las imágenes dibujadas fue privativo de los objetos materiales —alfarería, tejidos, instrumentos musicales - que acompañaron a la exposición fotográfica: el blanco y negro fue característico de lo representado en la foto. Pero también nos encontramos que la respuesta implicó lo «infotografiable», aquello que la imagen pierde pero que el acto de recepción en parte complementa: Miryam, una joven que reconoció a su abuelo en una imagen, dibujó su retrato en un margen de la hoja indicando como epígrafe el

11 Entre septiembre y octubre de 2005 gestionamos esta exposición, en forma conjunta con el Centro Cultural Nordeste de la Universidad Nacional del Nordeste, curada por Luis Príamo, y que contaba con alrededor de 100 imágenes de las más de 1000 tomadas por la fotógrafa a los pueblos indígenas del norte argentino entre 1958 y 1964.

12 Hay que tener en cuenta que históricamente estas comunidades comunicaron su memoria a través de la oralidad, mientras la visualidad no ocupó un lugar preponderante en esa transmisión. 
nombre del retratado, y en otro espacio del plano la figura de una mujer con largas uñas que se convertían a su vez en líneas envolventes. Junto a esta imagen, el epígrafe "Según la leyenda de la mujer (onsagoy mujer que come carne de hombre)» y transcribió parte de dicha leyenda ${ }^{13}$, la que según nos comentara luego, se la relataba de niña su abuelo muerto, aquel que - aún joven- reconoció en una foto. En su dibujo dividió el plano visual en dos ámbitos: el retrato de la imagen visualizada en la foto - su abuelo joven-y el de la leyenda, donde texto e imagen se integran. Planos que podrían aludir a una cuestión de la temporalidad — antes/ahora - y la espacialidad — barrio toba/espacio de exposiciónde la fotografía, pero en particular a tales aspectos ligados a una experiencia personal: lo que podríamos definir como la experiencia de la visualidad.

Si bien se argumenta sobre lo inacabable que caracteriza a la fotograficidad y por ello se afirma que la realización en fotografía jamás está terminada (Soulages, 2005), el acto de recepción y la posterior expresión plástica-verbal de Miryam complementan la estética de la realización con la estética de la recepción. Al decir de Nori, «El poder de la imagen es la fuerza de la interpretación que pueda darle la gente» (1976:4), más aún en este caso, cuando se trata de una comunidad capturada históricamente por la imagen, pero desconocedora de su existencia.

Sin duda que una vía a partir de la cual nosotros podemos analizar esta misma imagen del abuelo de Miryam, se realizaría desde el referente, los aspectos formales y la materialidad del objeto, mientras ella la aborda - a partir de una inflexión- desde su historia y la memoria personal y comunitaria, y por ello la imagen dispara hacia aspectos experienciales y complementa — probablemente en parte—, la «pérdida», rescatando el «resto».

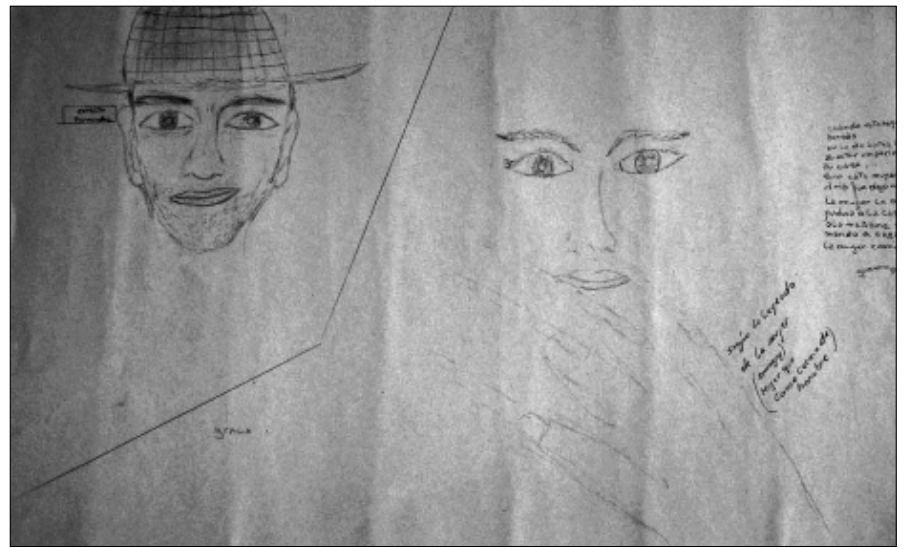

1. Dibujo de Miryam L. sobre su abuelo y la leyenda de la mujer osangoy. Respuesta a la visita a exposición fotográfica Aborígenes del Gran Chaco. Fotografías de Grete Stern, 2005.

13 Miryam, quien se había sentido muy consternada al ver la foto de su abuelo, comenzó a realizar estos dibujos y escritos cuando todo el resto de los jóvenes que participaron del taller ya habían concluido y comenzaron a hacer sus comentarios. Por ello su relato escrito se presentó inconcluso, y así lo hizo saber escribiendo al final: «quisiera seguir contando». Ello nos abrió las puertas para posteriores entrevistas con imágenes en su propia casa y en la de otros familiares. La parte de la leyenda que escribió dice: "Cuando esta mujer estaba en su periodo en lo de antes (sic) los indígenas decían que al estar en período no debían salir de su casa. Pero esta mujer se fue al río a tocar el río fue algo misterio. La mujer agarró un escalofrío y volvió a la casa. A la mañana siguiente se fue con su marido a cazar de cotorra. La mujer comía la cotorra sin cocinar... Y quisiera seguir contando". 


\section{LA DIMENSIÓN DOCUMENTAL: CONTRATOS DE VERACIDAD, ESTRATEGIAS MA- NIPULADORAS Y HUELLAS DE LA IMAGEN}

La fotografía es un sistema convencionalizado de representación. Éste supone que la imagen es un documento de las formas de representar, de los sistemas cognoscitivos de una época, de las expectativas visuales de un período. Se ve aquello que se espera ver, en función de ciertas maneras de hacer, de formas de visibilidad de esas maneras de hacer y de los aspectos que resultan significativos para un grupo social. «Lo fotografiable» es sólo una parte de lo visto, lo enfocado y lo percibido. Otro gran universo queda invisible, oscuro, sesgado, y está en nuestra capacidad crítica y analítica abordar ese documento teniendo en cuenta estos aspectos. Si la fotografía es una unicidad o trozo único de algo (Durand, 1998), deberíamos considerarla desde sus sesgos, partículas y entramados. Y así hemos tratado de hacer en nuestros trabajos previos sobre la imagen del indígena chaqueño, desmitificando el valor metonímico de la imagen que, en aquellas fotografías que por su consideración de «imágenes documentales» fueron concebidas y utilizadas como un reporte transparente de situaciones, formas de vida, materialidades y corporeidades de los indígenas del Chaco, en el contexto de un contrato de veracidad implícito de la sociedad occidental con la imagen fotográfica.

Aquellas fotografías producidas en contextos de sujeción y control, como las realizadas por la observación antropológica o la documentación de fotógrafos, fueron concebidas bajo el rótulo de «documentales» y valoradas en función de ese contrato de veracidad.

La consideración de documento de la fotografía suponía - en los contextos en que fueron obtenidas, tomando para el inicio de este análisis las pertenecientes a fines del siglo XIX y primeras décadas del siglo XX- no sólo su valor de «verdad» objetiva y de prueba irrefutable ${ }^{14}$, sino la negativa a atribuirle una valoración estética y menos aún, ética. Si bien dentro de las estrategias manipuladoras las cirugías fácticas de imagen podrían ser uno de los casos extremos en el cuestionamiento de ese estatus documental ${ }^{15}$, debemos tener en cuenta, sin embargo, que la verificación de tales cirugías proceden de nuestros análisis comparativos e indiciales de amplios corpus que nos permitieron constatar la manipulación del material fotográfico para la construcción de nuevas imágenes. Sin embargo, las cirugías no sólo son fácticas, sino también mentales, y ello es un elemento central en el corpus fotográfico del indígena chaqueño de la época señalada ${ }^{16}$ y también en épocas posteriores, incluso actuales: el recorte de lo que se ve, el silenciamiento y ocultamiento de lo que no se ve es central en la consideración de este «valor documental» de la imagen, pero difícilmente advertible por los consumidores de la época, que como gran parte de los receptores actuales, aceptan las imágenes desde un contrato de veracidad y transparencia. Asimismo, ¿cómo advertir los cambios de escala de ciertas imágenes, la construcción de nuevas imágenes a partir de la incorporación del color y más aún, la construcción de nuevos sentidos al incorporar epígrafes generalizadores o decididamente falsos de la imagen? Un ejemplo singular sobre estas estrategias manipuladoras fueron

14 Véase sobre la fotografía como prueba y verdad vinculada a la construcción de archivos Tagg (2005: 81-6).

15 Sobre el tema de las cirugías fácticas véase Alvarado (2001) y Giordano (2007).

16 Véase sobre este tema Giordano (2007: 84-7). 
las imágenes de Guido Boggiani de amplia difusión a principios del siglo XX en diferentes series postales: obtenidas a indígenas del Chaco paraguayo, una primera edición en postales estuvo dirigida por Robert Lehmann Nitsche ${ }^{17}$ y editada por la casa Rosauer de Buenos Aires, y tuvo la descripción que las anotaciones de Boggiani había consignado en su cuaderno personal. La aceptación en el coleccionismo de postales llevó a que otros editores seleccionaran algunas fotos para reeditarlas, ahora coloreadas, eligiendo aquellas que cubrían con las expectativas sociales de "lo indígena", expectativas que seguían reproduciendo imaginarios de la época colonial: la desnudez, el arte plumario, los tatuajes faciales fueron algunos de los indicadores que guiaron la selección y que sirvieron de espacio visual de manipulación a través del color. La creación de nuevas imágenes se enfatizaba con otra manipulación que fue la incorporación de epígrafes que ubicaban a estos indígenas en territorio argentino. Esta misma actitud se hizo presente en publicaciones realizadas en la época del Centenario de la emancipación y la independencia argentina (1910-1916), donde numerosos álbumes incorporaban datos etnológicos de la Argentina en los que las imágenes de Boggiani «documentaban» visualmente los grupos residentes en nuestro país.

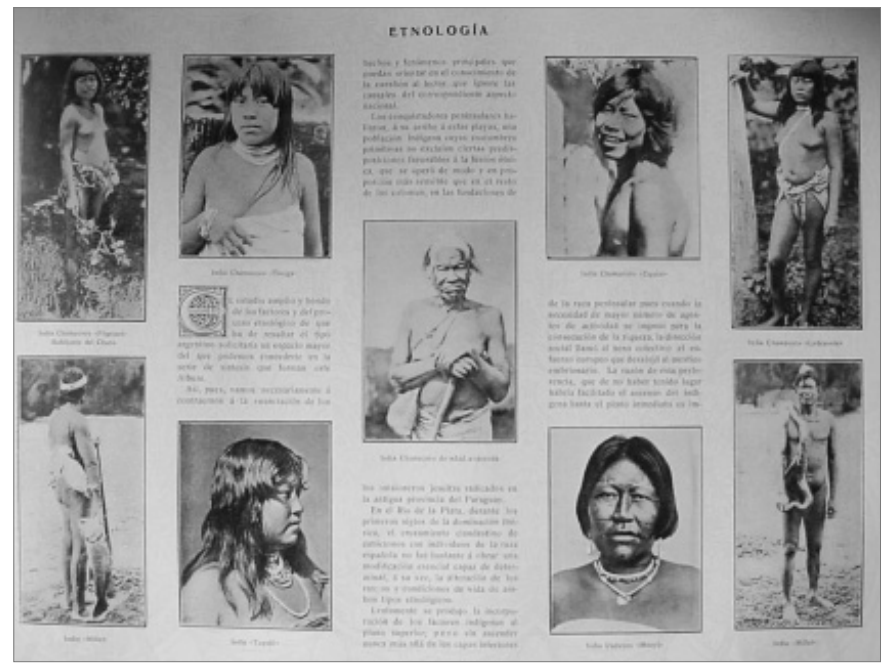

2. Álbum «1810-1910. La República Argentina en el Primer Centenario de su Independencia». Buenos Aires, Imprenta Rosso, 1910.

Ahora bien, al igual que en los recortes fácticos, estas estrategias manipuladoras las podemos advertir no sólo a partir de nuestra desconfianza respecto de la inocencia y transparencia de las imágenes - una actitud diferente a la que suponía un espectadorlector y hasta un académico de principios del siglo XX-, sino también desde un conocimiento amplio de un corpus al que pudimos acceder y a través de un cierto peritaje foren-

${ }_{17}$ Antropólogo alemán, fue director del Departamento de Antropología del Museo Nacional de La Plata (Argentina), utilizando profusamente la fotografía antropométrica. 
se del cuerpo del delito - para el caso de los recortes fácticos-y un seguimiento de los usos de las imágenes en contextos iconográficos diferentes para los que se obtuvieron ${ }^{18}$. Lo que implica que para la sociedad en su conjunto, que no realiza este tipo de análisis, la dimensión documental-objetiva de estas imágenes se sigue sustentando en el contrato de veracidad establecido con la fotografía.

Además de las cirugías, la invisibilidad u ocultamiento es otro fenómeno central en la consideración de la faz documental de la fotografía. ¿Cómo entender entonces la llamada Sublevación de Napalpí de $1924^{19}$ en lo que podríamos llamar la imagen desaparecida o la invisibilidad representada? La total invisibilidad de este hecho clave en la historia de los grupos indígenas chaqueños podría refutarse a partir de unas escasas imágenes que el antropólogo Lehmann Nitsche tomara a indígenas vilelas y tobas ubicados en la Reducción de Napalpí. Este académico perteneciente al Museo de La Plata, que llegó al escenario donde se produjo la matanza de indígenas pocas horas después de producidos los hechos con el objetivo de realizar trabajo de campo durante quince días, tomó -o hizo tomar a su asistente ${ }^{20}$ - fotografías que se conservan en el legado personal de este antropólogo alemán en el Instituto Iberoamericano de Berlín. El silenciamiento de los acontecimientos de Napalpí por parte de Lehmann Nitsche ha sido un tópico de discusión de la antropología argentina ${ }^{21}$; a ello se suma la supuesta invisibilidad de la masacre, que intentaremos abordar desde marcas presentes en las imágenes mencionadas.

Según la prensa de la época, funcionarios del Territorio no le permitieron acercarse a Lehmann y a su acompañante — considerados «testigos calificados de la tragedia»- al escenario de la masacre ${ }^{22}$. Las imágenes a las que nos referimos no muestran específicamente el escenario de muerte que caracterizó este conflicto ${ }^{23}$ : se trata de retratos individuales y grupales - los primeros siguiendo los parámetros del retrato antropométrico fle-

18 Sobre un análisis desde una «arqueología de la imagen», véase Alvarado y Giordano (2007).

19 La Reducción civil de Napalpí creada y administrada por el Estado Nacional en 1911 fue, junto a la de Bartolomé de las Casas en Formosa, las únicas de este tipo en la Argentina. En 1924 se produjo la llamada "Sublevación de Napalpí» desencadenada por factores de índole político-económico, maltrato y explotación de que eran objeto los indígenas, en un contexto de difusión de ideas milenaristas entre los pueblos indígenas chaqueños. La misma tuvo un trágico desenlace con intervención armada enviada por el gobernador del Territorio Nacional del Chaco, Fernando Centeno. Sobre los acontecimientos de Napalpí en 1924 véase, entre otros, Cordeu y Siffredi, 1971, Iñigo Carrera, 1984, Tamango, 2001, Gordillo, 2004. Actualmente Napalpí se ha transformado en un espacio aislado e improductivo que debido a las dificultades del sector agropecuario chaqueño en su conjunto y a la falta de asesoramiento para los productores indígenas ha provocado un incesante éxodo hacia las ciudades, en especial de jóvenes que pretenden hallar trabajo, asistencia sanitaria y en especial participar de los beneficios sociales y culturales la sociedad nacional (Censabella, 1999).

20 La prensa de la época hace referencia a la presencia de un «asistente» junto a Lehmann Nitsche. Heraldo del Norte, Corrientes, 27/VI/1925. En otros trabajos de campo lo había acompañado el entomólogo y fotógrafo Carlos Bruch, pero no podemos afirmar que fuera su «asistente» en esta oportunidad ya que el mismo se había retirado del Museo de La Plata.

21 Véase Gordillo, 2004.

22 Heraldo del Norte, Corrientes, 27/VI/1925. Este número especial del Heraldo del Norte fue realizado a casi un año de la Matanza dado que este diario, originalmente llamado Heraldo del Chaco, sufrió la persecución política por enfrentarse al gobierno territoriano, trabajó en la clandestinidad y en 1925 editó este número extraordinario sobre Napalpí en la ciudad de Corrientes. Sobre la presencia de Lehmann Nitsche y su acompañante el día 19 de julio de 1924, este diario dedica largos párrafos.

23 No hay coincidencia sobre la cantidad de muertos el día 19 de julio en que se produjo la masacre: algunos refieren 200 muertos y otros cerca de 800 . La diferencia podría sustentarse en considerar las persecuciones de los 90 días posteriores o sólo aquellos que se contabiliza el día de la matanza. La comunidad hace referencia a la primera cifra. 
xibilizado, si lo comparamos con la producción previa de Lehmann Nitsche ${ }^{24}$ - edificios de la administración de la Reducción y una imagen que muestra un avión con un grupo de personas delante y detrás del mismo. Todos ellos tienen algún tipo de inscripción en su reverso, incluso los nombres de algunos retratados se encuentran consignados, además de su pertenencia étnica, siendo en su mayoría identificados como vilelas y tobas.

Desde una primera mirada no tendríamos razones para vincular este corpus con la masacre, y podríamos suponer que se trata de un relevamiento documental realizado por Lehmann en otra de las visitas al $\mathrm{Chaco}^{25}$. Sin embargo, proponemos tomar estas catorce imágenes que, desde nuestra perspectiva, también hablan del conflicto a través de estrategias de «desapariciones forzadas» ${ }^{26}$ en conceptos de Grüner, y desde la mirada de algunos descendientes de testigos de la matanza, simbolizan otra cara de la historia.

Desconocemos si estas imágenes de Napalpí que hoy se conservan constituyeron el corpus total producido en la visita de 1924 de Lehmann; si creemos a lo expresado por la prensa de la época, podría entenderse que no pudo obtener otras imágenes, pero igualmente nos queda un margen para la duda, en particular por la importancia que este antropólogo daba a las fotografías en sus investigaciones. Podríamos suponer también que la no representación pudo haber surgido de una intención de no caer en lo que hoy se alude como «estetización del horror $»^{27}$, o porque hubo una censura premeditada por parte de Lehmann para no reconocer el fracaso reduccional que él mismo había defendido, o por la censura impuesta por las autoridades para silenciar u ocultar ese horror. De cualquier forma, no queremos renunciar a comprender Napalpí por el camino de la supuesta no representación o del silenciamiento visual, como históricamente se ha afirmado.

Si nos centramos en el referente, estas catorce fotos legitiman visualmente un ambiente apacible con indígenas «amigos» que posan ante la cámara y que poco indicaría el contexto de sangre que se denunciaba — y aún se denuncia-, concluyó la "sublevación» o «matanza» ${ }^{28}$ de Napalpí. Por lo tanto, estas imágenes coinciden con los fundamentos del Estado y parte de la prensa nacional y territoriana respecto de los acontecimientos ocurridos en esa Reducción. Estos indígenas amigos eran especialmente tobas y vilelas ${ }^{29}$ según inscripciones que Lehmann Nitsche incorporara a las fotos, grupo minoritario que hoy se considera "desaparecido» en el Chaco. Esta condición de «amigos» nos aparecía desde el referente una señal en nuestra lectura, pero en la memoria de los sobrevivientes de la matanza y sus descendientes los vilelas fueron señalados como los «entregadores»

Sobre la producción de Lehmann Nitsche en el Chaco véase Giordano, 2005b.

5 Se sabe que Lehmann Nitsche visitó en otras oportunidades el Chaco, pero no se tienen las fechas exactas ni los lugares que recorrió. En 1906 comenzó su etapa de campañas al Norte argentino y a Bolivia (1906, 1921, 1924), donde efectúa investigaciones acerca de distintos grupos étnicos y sitios arqueológicos (Lehmann Nitsche 1904, 1907).

26 Refiere tanto a desapariciones retóricas como literales, que permiten dejar «vacíos» que completamos con nuestras expectativas (Grüner, 2002: 69).

27 Grüner se pregunta "¿cómo representar lo irrepresentable, sin caer en la trampa de lo sublime, de una estetización del espanto?» (2002: 66).

28 Sobre el manejo discursivo en la prensa de la época de los sucesos de Napalpí véase Giordano (2005, 131-7).

29 Los vilelas estaban ubicados en la zona cercana a Resistencia, capital del Chaco. Al crearse la Reducción de Napalpí, su organizador, Enrique Lynch Arribálzaga, llevó un grupo de indígenas de esta etnia que se ubicaron en tierras de la administración de la Reducción. En la actualidad se afirma que los vilelas han desaparecido, en particular su lengua, aunque en la comunidad de Colonia aborigen hay descendientes de aquellos vilelas que incluso conservan la lengua, pero que se invisibilizan entre los tobas. 
a las autoridades policiales del lugar donde se encontraban los «sublevados» ${ }^{30}$. Juan, al observar varias de las fotos en que vilelas y tobas llevan un brazalete en sus brazos, señala que su abuela — quien había sobrevivido a la matanza - le había relatado que:

... el brazalete era una forma de identificar los buenos de los malos. Durante la época de la matanza y la persecución posterior el brazalete identificaba a los buenos, los que estaban en la Reducción y el que no tenía esa señal era un salvaje. Mi abuela me lo contó hace mucho tiempo, yo dudaba, pero ahora veo esa marca acá en la imagen y eso se vincula con la matanza. ${ }^{31}$

Esa «marca» en la imagen vinculaba la imagen apacible y amistosa con uno de los hechos más sangrientos que viviera esa población, también constituía un puente con la memoria familiar de Juan pero a la vez «documentaba» la «entrega» de los vilelas ${ }^{32}$, grupo al que dirigió la mirada.

Sin embargo, si nos atenemos a las inscripciones de las imágenes en el reverso, muchos de los hombres que tienen brazalete están identificados por Lehmann como tobas, que confirma tanto la versión oficial como de parte de la comunidad de los «tobas amigos", es decir, aquellos que acompañaron las decisiones de la administración y de la fuerza policíaca.

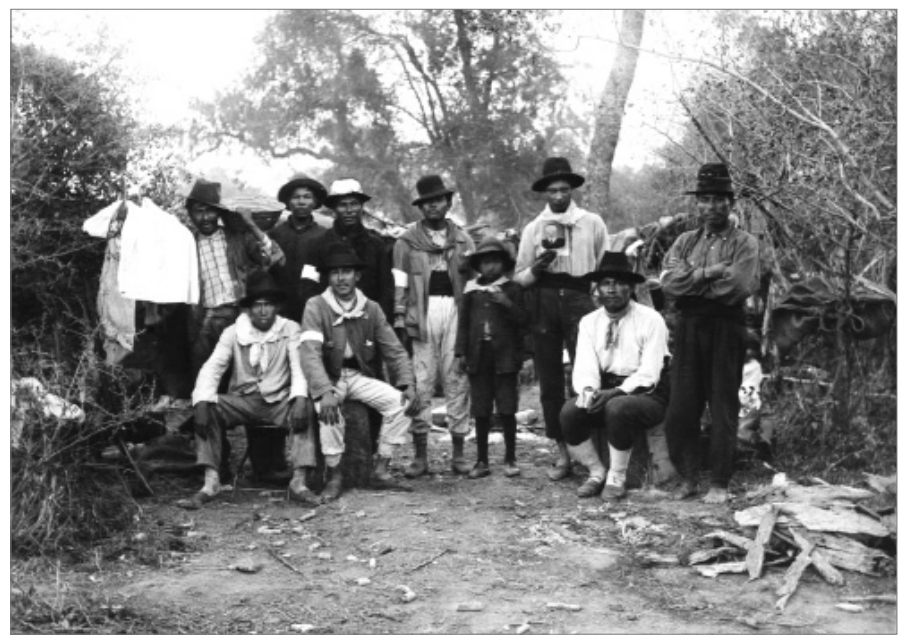

3. Lehmann Nitsche (atrib). «Toba, Napalpí», 1924. Legado Robert Lehmann Nitsche. Instituto Iberoamericano de Berlín.

30 Entrevista a Juan Chico. Resistencia, 26 de junio de 2009. Juan Chico es un intelectual toba (qom), perteneciente a la comunidad de Colonia Aborigen (ex Reducción de Napalpí), y recientemente ha publicado junto a Mario Fernández el libro El llamado de la sangre.

31 Entrevista a Juan Chico. Resistencia, 26 de junio de 2009.

32 En la actualidad se dice que no existen vilelas en la comunidad, aunque algunos de ellos se han «invisibilizado" por haber sido señalados por tobas y mocovíes como los «entregadores» en la Sublevación. "Hay vilelas, y hay gente que habla vilela, pero no lo dice, prefiere hablar en toba». Entrevista a Juan Chico. Resistencia, 26 de junio de 2009. 
Sin dudas esto refuerza la afirmación de Soulages que «La fotografía no es ya una cita de la realidad, sino una historia puesta en escena» (2005: 85). Pone en escena un conflicto sin referirse directamente a él — si nos remitimos solamente a «lo fotografiado»—, pero si nos atenemos a «lo fotografiable» este corpus nos remite a una historia más compleja, tanto que una sola imagen que aún no hemos considerado del conjunto de las catorce de Lehmann Nitsche completa otros aspectos de la matanza y de la memoria comunitaria de Napalpí que nos permitieron incluir las catorce imágenes al contexto de la matanza. Se trata de una imagen donde se presenta un avión en el que se distingue " 2 Chaco" con su piloto en la cabina, un grupo de hombres delante del avión —razón por la que no se distingue toda la inscripción que lleva el mismo-, varios de ellos con fusiles Winchester en la mano, un policía del Territorio y en un segundo plano un pequeño grupo de indígenas, algunos de los que aparecen en el resto de las imágenes. La foto tiene una inscripción en el reverso que dice: «Flugzeug gegen den Indianeraufstand» («Avión contra levantamiento indígena» $\left.{ }^{33}\right)$, lo que sitúa claramente esta imagen en el contexto de la "Sublevación»o «Matanza", y lo hace presente a Lehmann por encontrarse representado entre el grupo que rodea el avión.

La prensa opositora al gobierno de la época de la matanza y la memoria de los sobrevivientes y sus descendientes han referido a la presencia de un avión de Aerochaco que sobrevoló la zona en la que se encontraban tobas y mocovíes a la espera de promesas de resolución del conflicto planteado al gobierno territoriano. La prensa oficialista decía que el día 18 de julio se había enviado un avión para supervisar el "campamento de los alzados», mientras el periodismo opositor señaló que cuando los cuadros de gendarmería y policía ya estaban desplegados para el ataque el aeroplano tripulado por el sargento Esquivel sobrevoló el campamento indígena, y que siguió haciéndolo «siniestramente» luego de la matanza para confirmar a la policía que no había peligro ${ }^{34}$.

Al presenciar esta imagen, gestos y voces confluían en los trabajos de la memoria individual ligada a la memoria comunitaria y en afirmaciones visuales que la fotografía suponía. Nos decía Juan:

Hay dos versiones: en nuestra comunidad unos dicen que el avión pasó días previos de la matanza para hacer reconocimiento y que ese día sobrevoló y el ruido hizo que la gente saliera porque estaba expectante de la promesa del gobernador. Otra versión, que viene de los vilelas, dice que el avión tiró caramelos y que eso hizo que la gente se juntara en un lugar y favoreció el ataque de la policía. A mi este avión de la foto me impresiona, pero me interroga si la foto es antes o después de la matanza. ${ }^{35}$ [A ello completaba David, presente en el mismo acto de recepción junto a Juan, diciendo:] Para mi el avión es la imagen de la victoria. Parece decir «hemos terminado el trabajo», ese es el mensaje. Para mí es el después, no el antes. ${ }^{36}$

La traducción es nuestra.

Heraldo del Norte, Corrientes, 27/VI/1925.

Entrevista a Juan Chico. Resistencia, 26 de junio de 2009.

Resistencia, 26 de junio de 2009. 


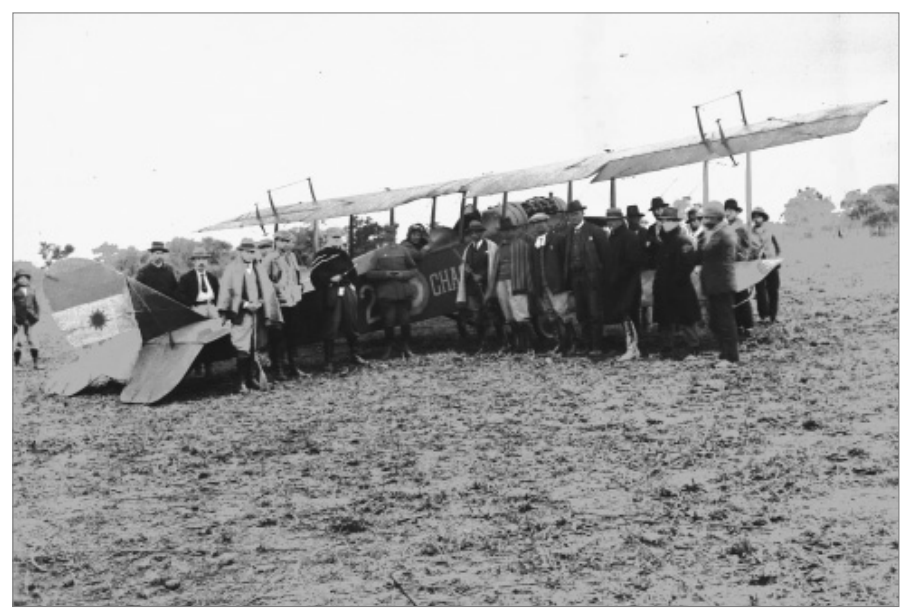

4. Lehmann Nitsche (atrib) ${ }^{37}$. «Avión contra levantamiento indígena», 1924.

Legado Robert Lehmann Nitsche. Instituto Iberoamericano de Berlín.

Brazalete en brazos vilelas y tobas, avión con funcionarios y el mismo Lehmann Nitsche e indígenas en un escenario apacible y desde una "documentación de escena» se convierten en huellas visuales de los testimonios orales transmitidos generacionalmente y de las expresiones de parte de la prensa de la época. Huellas que permiten completar el «resto» tanto desde los documentos de la época como desde los testimonios de la comunidad involucrada, donde la memoria oral ha sido la depositaria de la mayoría de las huellas de la masacre.

Si bien el acercamiento de imágenes a la actual comunidad de Napalpí revela que le otorgan el valor objetivo y transparente a la imagen, y se orientan hacia la identificación del referente, informantes como Juan Chico, quien se ha dedicado a recopilar la memoria de los ancianos, revelan otra mirada, que pendula entre el «así era» — «quisiera esa foto del edificio de la Reducción para mostrar cómo era», expresa Juan ante una fotografíay la búsqueda del resto de la imagen donde a partir de elementos identificables se refiere a aspectos no presentes o invisibilizados en la representación. Probablemente ello confirme la afirmación que suele repetirse en muchos ámbitos y que expresa que esta comunidad vive "...un eterno Napalpí. Un Napalpí actualizado, un Napalpí vigente. La masacre de todos los días» (Solans, 2008: 1).

El análisis que los indígenas de la actual Colonia Aborigen (ámbito de la Reducción de Napalpí) hacen hoy respecto de estas imágenes pone de manifiesto el reconocimiento de su valor metonímico, aunque en el acto de inflexión las vinculan con su memoria comunitaria y le atribuyen significados, relaciones y lazos particulares que visibilizan lo que la imagen silencia, enfatizando el valor parcial de la documentación fotográfica.

Ello también se advierte cuando les acercamos otro conjunto de imágenes de Napalpí obtenidas en 1936 por Lorenzo Domínguez, médico enviado por la Comisión Honoraria de Reducciones de Indios para que realizara observaciones en esa Reducción. Al observar

37 Esta foto no pudo haber sido obtenida por Lehmann ya que él se encuentra representado en la misma. Sin embargo, atribuimos todas estas fotos a este antropólogo, ya que fueron obtenidas dentro de su proyecto de trabajo de campo en Napalpí. 
una serie de imágenes de la cacica mocoví Mercedes Dominga —sobreviviente de Napalpí- asistiendo al acto de juramento a la bandera por parte de la población indígena de la Reducción, la respuesta de varios de los entrevistados es el silencio, mientras Juan dice: «Yo quiero esas imágenes de la Cacica, estoy averiguando sobre ella, no entiendo cómo hizo para sobrevivir a las persecuciones después de la matanza, si duraron tres o cuatro meses las persecuciones». Estas imágenes simbolizan para nosotros como analistas la presencia de fuertes mecanismos de aculturación, control y vigilancia que el Estado $\mathrm{Na}$ cional llevó adelante en las Reducciones y en especial en Napalpí luego de la «sublevación de 1924», sumado a la política de «incorporación a la nacionalidad» a partir de la emisión de los documentos y la jura de la bandera. Juan las percibe —en forma complementaria a nuestra mirada-como una parte «faltante» de su historia comunitaria vinculada a la matanza, la que ubica a la cacica Dominga en una nueva relación con esa historia.

En esta diversidad de miradas, las nuestras, la de la sociedad hegemónica contemporánea a las tomas y las comunidades indígenas actuales, la concepción de la imagen como documento presenta una tensión entre lo que la fotografía captura y lo que su mirada dispara o libera y al mismo tiempo limita o silencia, en ocasiones filtrados por legitimaciones institucionales. Entre estos dos extremos la memoria se impone como dimensión ineludible vinculada a los actos de apropiación, atribución y devolución de las imágenes fotográficas, donde nuevamente las instituciones juegan un rol fundamental, no sólo las que mantienen capturadas las imágenes en sus archivos, sino aquellas que las reproducen o las exponen sin una crítica al documento y también las mismas instituciones indígenas cuyas demandas aún no se han canalizado respecto de la imagen. Un intelectual indígena mocoví, Juan Carlos, expresaba al respecto: "...eso [la foto] fue un arma, un elemento de conquista. Ellos vinieron, observaron y se fueron, y se llevaron las fotos, pero son nuestras, si nosotros no queremos no pueden usarlas» ${ }^{38}$.

\section{ROLES DE LA IMAGEN: HACIA UNA ÉTICA DE LA IMAGEN DEL OTRO}

La imagen es un mecanismo de poder: tanto en su producción como en los ámbitos en que circula y se recepciona se puede constatar esta afirmación. Las imágenes producidas por el Estado argentino sobre los indígenas chaqueños a fines del siglo XIX y principios del XX circularon en las Memorias e informes de los militares ${ }^{39}$ o funcionarios que participaron de la acción militar-colonizadora; ellas se enmarcan en un discurso del "acuerdo", desplazando, ocultando y negando el conflicto y la violencia armada. Si nos ubicamos en la percepción de gran parte de la sociedad decimonónica respecto de la fotografía como sinónimo de verdad, estas imágenes cumplen el rol de legitimar un discurso pacífico y una ocupación inofensiva del espacio chaqueño. La imagen es legitimadora de un proyecto político-militar y constructora de hegemonías, como también lo fue en el caso de aquellas obtenidas en el contexto de las misiones franciscanas en la región chaqueña que legitiman el «esquema civilizatorio» impuesto sobre los indígenas chaqueños (Giordano y Méndez, 2005). Se sustenta por lo tanto en su presunción de «testigo», y no

\footnotetext{
Entrevista a Juan Carlos M. Resistencia, 24 de junio de 2009.

39 Entre ellos, los producidos por fotógrafos que acompañaron la gran Expedición Victorica de 1884 y las campañas de pacificación que le siguieron a aquella.
} 
se le reconoce valor estético, sino esencialmente testimonial. Un testimonio, sin lugar a dudas, sesgado, pero que en el contexto de la época se lo valoraba por su verdad y no por su verosimilitud ${ }^{40}$.

Este rol de la imagen, como legitimadora de discursos y prácticas de grupos de poder, no se hace presente en la lectura de las imágenes que hicieran tobas, mocovíes y wichí en los actos de recepción actuales. Ante las imágenes mencionadas, su mirada se orientaba a detalles de la representación que punzaban su atención: los uniformes militares que vestían algunos indígenas en estas representaciones del «acuerdo» y las construcciones edilicias que los franciscanos hicieran entre los wichí de Nueva Pompeya. En ambos casos, hacían referencia a la noción de «testigo» de la imagen: "...son testigos mudos»" expresaba Humberto en Juan José Castelli. Testigos incuestionables e inclaudicables, a los que no se criticaba. Y más aún si nos atenemos a las imágenes comentadas previamente sobre Napalpí: ciencia antropológica, instituciones como el Museo de La Plata (al que pertenecía Lehmann Nitsche) y Estado territoriano y nacional intervinieron desde ese entramado de poder abordado por Foucault (1978) que nos permite advertir la maraña de relaciones que penetran en el cuerpo social. Claro ejemplo del poder de la imagen al testificar a través de lo visto y no visto, pero también, las políticas de la memoria y olvido que hicieran que estas imágenes sean desconocidas hasta hoy por las comunidades indígenas chaqueñas.

Si contemplamos el rol comercial y editorial que tuvo históricamente la imagen del indígena y que sigue teniendo en la actualidad, las manipulaciones tienen entonces fundamentos económicos más allá de la forma en que estos medios han construido sujetos históricos.

La cuestión de los archivos y el acceso a los mismos, la organización de grandes exposiciones que recorren países pero que no llegan en varios casos a los lugares donde las imágenes fueron captadas, son otros indicadores de la necesidad de debatir no sólo sobre la estética de la imagen del otro, sino también de la ética.

Los roles de la imagen en ocasiones se vinculan con los grados de iconicidad e indicialidad que a su vez varían dependiendo de sus referentes (Mandoki, 2008: 108). Ello ha posibilitado la utilización de estrategias manipuladoras y la construcción de falsas imágenes y, por lo tanto, la configuración de sujetos históricos —el indígena chaqueñoy a reactualizaciones permanentes del imaginario sobre dichos sujetos que hacen caso omiso a una ética de la imagen. Si bien las discusiones sobre la verdad y lo verosímil podría ayudarnos a comprender las alteraciones, trastrocamientos y falsedades de la imagen, en medios científicos, periodísticos e institucionales - como Museos, universidades, etc.- donde estas cuestiones son tema de discusión y se advierte claramente la diferencia entre ambos conceptos, se siguen utilizando, sin embargo, estrategias colonialistas de la imagen, basadas en su supuesta objetividad y valor de verdad. Asimismo, la captura de fotografías en los archivos, la elaboración de exposiciones o divulgaciones acríticas donde la imagen sigue planteándose como autoridad e instrumento didáctico realista (Edwards, 2006), enfatizan la transparencia de la imagen sin orientar las expectativas del público hacia la naturaleza polisémica y fragmentaria de la fotografía, donde el indígena es un objeto museístico — del pasado- pero no un miembro de la sociedad actual. Así,

40 Sobre la distinción entre «verdad» y «verosilimitud» en la imagen fotográfica véase García Canclini, 1982.

41 Entrevista a Humberto. Juan José Castelli, 21 de agosto de 2007. 
se consolida la actitud de pensar «en» fotografías y no «con» las fotografías incluso en las producciones contemporáneas ${ }^{42}$.

Todo ello nos lleva a plantear la necesidad de discutir no sólo sobre la «sinceridad estética» en las producciones históricas y reproducciones contemporáneas, sobre los modos hegemónicos de construcción de sujetos históricos y de identidades sociales, sino también, y esencialmente, sobre la ética de las producciones contemporáneas, la ética de la circulación histórica de imágenes del indígena y la ética de la recepción de estas imágenes en la actualidad. Ello se funda en que «la ética de la transparencia no sería sólo de la producción, sino también de la textualización e interpretación fotográficas» (Lizarazu, 2008: 15). Sólo a través de acciones, textualizaciones e interpretaciones que tengan por objeto dimensionar el rol de la ética de la imagen se podrán producir miradas más amplias que se integren en la maraña de relaciones de poder en la que participa la fotografía.

\section{REFERENCIAS}

Alvarado, Margarita. (2001). Pose y montaje en la fotografía mapuche. Retrato fotográfico, representación e identidad. En Margarita Alvarado y otros, Mapuche. Fotografías Siglos XIX y XX. Construcción y montaje de un imaginario. Santiago: Pehuén.

Alvarado, Margarita y Mariana Giordano. (2007). Imágenes de indígenas con pasaporte abierto: del Gran Chaco a la Tierra del Fuego. Revista Magallania 35 (2): 15-36. Instituto del Hombre Austral. Universidad de Magallanes, Punta Arenas.

Baxandall, Michael. (1978). Pintura y vida cotidiana en el Renacimiento. Arte y experiencia en el Quatroccento. Barcelona: Gustavo Gili.

Belting, Hans. (2007). Antropología de la imagen. Buenos Aires: Katz Editores.

Censabella, Marisa. (1999). Las lenguas indígenas de la Argentina. Una mirada actual. Buenos Aires: Eudeba.

Cordeu, Edgardo y Alejandra Siffredi. (1971). De la algarroba al algodón. Movimientos milenaristas en el Chaco argentino. Buenos Aires: Juárez editor.

Durand, Régis. (1998). El tiempo de la imagen. Ensayo sobre las condiciones de una historia de las formas fotográficas. Salamanca: Universidad de Salamanca.

Edwards, Elizabeth. (2006). Replantear la fotografía en el museo etnográfico. En Juan Naranjo (ed), Fotografía, antropología y colonialismo (1845-2006) (pp. 251-280). Barcelona: Gustavo Gili.

Foucault, Michel. (1978). Microfísica del poder. Madrid: La Piqueta.

García Canclini, Néstor. (1988). Fotografía e ideología: sus lugares comunes. Hecho en Latinoamérica. Segundo Coloquio Latinoamericano de Fotografía. México: Instituto Nacional de Bellas Artes.

42 Para una referencia de las discusiones filosóficas suscitadas por la difusión y consumo de la fotografía etnográfica chaqueña en contextos y circuitos consagrados al arte (museos, galerías, etc.), véase Reyero, 2009. 
Giordano, Mariana. (2003). Convenciones iconográficas en la construcción de la alteridad. Fotografías del indígena del Gran Chaco. En II Congreso Internacional de Teoría e Historia de las Artes-X Jornadas del CAIA: Discutir el canon. Tradiciones y valores en crisis (pp. 147-160). Buenos Aires: CAIA.

-. (2004). Grete Stern y el Chaco. XXIV Encuentro de Geohistoria Regional (275-284). Resistencia, IIGHI-CONICET.

-. (2005a). Discurso e imagen sobre el indígena chaqueño. La Plata: Al Margen.

- (2005b). Fotografía y Ciencia Antropológica en el Gran Chaco. En Cuadernos de Antropología e Imagem 14: 55-76. Universidade Estadual do Rio de Janeiro.

- (2007). Falsas imágenes, falsas memorias en la fotografía etnográfica. En IV Congreso Internacional de Teoría e Historia del Arte - XII Jornadas de CAIA: 83-96. Buenos Aires, CAIA.

Giordano, Mariana y Alejandra Reyero. (2009). La representación fotográfica de la sonrisa en las imágenes chaqueñas de Guido Boggiani y Grete Stern. Inédito.

Gordillo, Gastón. (2004). Landscapes of Devils: Tensions of Place and Memory in the Argentinean Chaco. Durham: Duke University Press.

Iñigo Carrera, Nicolás. (1984). La violencia como potencia económica. Chaco 18701940. Buenos Aires: CEAL.

Lehmann Nitsche, Robert. (1904). Etudes anthropologiques sur les indiens takshik du Chaco Argentin. Revista del Museo de La Plata. Taller de Publicaciones, T. XI.

- (1907). Estudios antropométricos sobre chiriguanos, chorotes, matacos y tobas. Revista del Museo de La Plata.

Lizarazo, Diego. (2008). El dolor de la luz. Una ética de la realidad. En Ireri de la Peña (coord.), Etica, poética y prosaica. Ensayos sobre fotografía documental (pp. 11-29). Madrid: Siglo XXI.

Mandoki, Katya. (2008). Fotos, mentiras y video. En Ireri de la Peña (coord.), Ética, poética y prosaica. Ensayos sobre fotografía documental (pp.104-132). Madrid: Siglo XXI.

Mitchell, W. J. T. (2003). Mostrando el ver. Una crítica a la cultura visual. Estudios Visuales 1: 17-40. Murcia: CENDEAC.

Penhos, Marta. (2005). Frente y perfil. Fotografía y prácticas antropológicas y criminológicas en Argentina a fines del siglo XIX y principios del XX. En Marta Penhos y otros. Arte y Antropología en la Argentina (pp. 17-64). Buenos Aires: Fundación Telefónica/Fundación Espigas/FIAAR.

Reyero, Alejandra. (2009). ¿La fotografía etnográfica puede ser objeto estético? Boletín de Estética. Programa de Estudios en filosofía del Arte. Centro de Investigaciones Filosóficas. Obtenido el 26 de septiembre desde <http://www.boletindeestetica.com. ar/monografias/Alejandra-Reyero-La-fotografia-etnografica.rtf $>$.

Ricoeur, Paul. (2008). La memoria, la historia, el olvido. Buenos Aires: Fondo de Cultura Económica.

Solans, Pedro Jorge. (2008). Crímenes en sangre. Resistencia: Librería de La Paz.

Sontag, Susan. (2006). Sobre la fotografía. Buenos Aires: Sudamericana.

Soulages, Francois. (2005). Estética de la fotografía. Buenos Aires: La Marca. 
82

-. (2001). Desde una estética de la fotografía a una estética de la imagen. En Universo fotográfico. Revista de fotografía 4, año III. Madrid, Universidad Complutense de Madrid.

Tagg, John. (2005). El peso de la representación. Ensayos sobre fotografías e historias. Barcelona: Gustavo Gili.

Tamagno, Liliana. (2001). Los tobas en la casa del hombre blanco. Identidad, memoria y utopía. La Plata: Al Margen.

Recepción: agosto de 2009 Aceptación: septiembre de 2009 